OPEN ACCESS

Edited by:

Damiana Leo,

University of Mons, Belgium

Reviewed by:

Jolanta Orzelska-Gorka, Medical University of Lublin, Poland

Rafael Roesler,

Federal University of Rio Grande do

Sul, Brazil

${ }^{*}$ Correspondence: Hongxin Dong

h-dong@northwestern.edu

Specialty section:

This article was submitted to

Neuropharmacology,

a section of the journal

Frontiers in Neuroscience

Received: 01 March 2021 Accepted: 07 September 2021 Published: 06 October 2021

Citation:

McClarty B, Rodriguez G and

Dong $H$ (2021) Dose Effects of Histone Deacetylase Inhibitor

Tacedinaline (Cl-994) on

Antipsychotic Haloperidol-Induced Motor and Memory Side Effects

in Aged Mice.

Front. Neurosci. 15:674745 doi: 10.3389/fnins.2021.674745

\section{Dose Effects of Histone Deacetylase Inhibitor Tacedinaline (Cl-994) on Antipsychotic Haloperidol-Induced Motor and Memory Side Effects in Aged Mice}

\author{
Bryan McClarty, Guadalupe Rodriguez and Hongxin Dong* \\ Department of Psychiatry and Behavioral Sciences, Feinberg School of Medicine, Northwestern University, Chicago, IL, \\ United States
}

Background: Elderly patients treated with antipsychotic drugs often experience increased severity and frequency of side effects, yet the mechanisms are not well understood. Studies from our group indicate age-related histone modifications at drug targeted receptor gene promoters may contribute to the increased side effects, and histone deacetylase (HDAC) inhibitors entinostat (MS-275) and valproic acid (VPA) could reverse typical antipsychotic haloperidol (HAL) induced motor-side effects. However, whether such effects could be dose dependent and whether HDAC inhibitors could improve memory function in aged mice is unknown.

Methods: We co-treated selective class $1 \mathrm{HDAC}$ inhibitor tacedinaline (Cl-994) at different doses $(10,20$, and $30 \mathrm{mg} / \mathrm{kg})$ with $\mathrm{HAL}(0.05 \mathrm{mg} / \mathrm{kg})$ in young (3 months) and aged (21 months) mice for 14 consecutive days, then motor and memory behavioral tests were conducted, followed by biochemical measurements.

Results: Cl-994 at doses of 10 and $20 \mathrm{mg} / \mathrm{kg}$ could decrease HAL-induced cataleptic episodes but only $20 \mathrm{mg} / \mathrm{kg}$ was sufficient to improve motor coordination in aged mice. Additionally, Cl-994 at 10 and 20 mg/kg mitigate HAL-induced memory impairment in aged mice. Biochemical analyses showed increased acetylation of histone marks H3K27ac and H3K18ac at the dopamine 2 receptor (D2R) gene (Drd2) promoter and increased expression of the Drd2 mRNA and D2R protein in the striatum of aged mice after administration of $\mathrm{Cl}-994$ at $20 \mathrm{mg} / \mathrm{kg}$.

Conclusions: Our results suggest $\mathrm{Cl}-994$ can reduce HAL-induced motor and memory side effects in aged mice. These effects may act through an increase of acetylation at the Drd2 promoter, thereby restoring D2R expression and improving antipsychotic drug action.

Keywords: aging, antipsychotics, histone deacetylases, histone acetylation, epigenetics 


\section{INTRODUCTION}

Aged patients, especially those with psychosis and neurodegenerative disorders combining neuropsychiatric symptoms, are often prescribed antipsychotic and antidepressant medications to treat the severe symptoms (Cummings et al., 1994; Cohen-Mansfield, 2001; Aupperle, 2006; Kamble et al., 2008; Gareri et al., 2014). For instance, typical and atypical antipsychotics have been administered to help manage neuropsychiatric symptoms in Alzheimer's disease (AD) patients, and studies have revealed modest efficacy of typical antipsychotics in dementia patients with neuropsychiatric symptoms (Schneider et al., 1990; Zaudig, 2000; Aupperle, 2006; De Deyn et al., 2013; Tampi et al., 2016). However, elderly ( $>65$ yo) patients prescribed typical antipsychotics have shown an increase severity and frequency of extrapyramidal side effects (EPS), (Zaudig, 2000; Alexopoulos et al., 2004; Aupperle, 2006; Gareri et al., 2014). EPS typically include acute dyskinesias, tardive dyskinesia, and Parkinsonism's (Blair and Dauner, 1992; Casey, 2004, 2006; Meltzer, 2013), all of which can be distressing and substantially affect the daily life and activities of these patients. Studies have indicated changes in the dopaminergic system of aged brains, which could be a potential factor influencing age-related sensitivities to typical antipsychotic drugs. Dopamine 2 receptors (D2Rs) are the main target for typical antipsychotics. An un-proportional ratio of dopamine and dopamine receptors, or excessive blockade of dopamine receptors in the basal ganglia circuits have been postulated to contribute to the pharmacodynamic changes in aged patients (Blair and Dauner, 1992), thus increasing the susceptibility of EPS in elderly patients to the antipsychotic drugs (Peluso et al., 2012; McClarty et al., 2018). Another study investigated the binding potential to D2Rs in the striatum of patients with neuropsychiatric symptoms of $\mathrm{AD}$ or $\mathrm{AD}$ alone and found that the binding potential in the patients with severe neuropsychiatric symptoms was significantly lower (Tanaka et al., 2003). These studies suggest that the dopaminergic system undergoes changes during aging, and such changes could influence drug efficacy and behavioral responses.

The mechanisms of aging-induced changes of the dopaminergic system in the brain remain unclear. Studies from our group have suggested that histone modifications at the $\mathrm{D} 2 \mathrm{R}$ gene $(\mathrm{Drd} 2)$ promoter, may be one of the factors contributing to the increased sensitivity of aged patients to antipsychotic side effects (Montalvo-Ortiz et al., 2017). We found that histone acetylation is decreased at the $\operatorname{Drd} 2$ promoter, impacting the expression and function of D2R, thereby affecting drug action. HDAC inhibitors entinostat (MS-275) and valproic acid (VPA) were able to restore acetylation levels at $\mathrm{Drd} 2$ and D2R expression, alleviating haloperidol (HAL) induced motor side effects (Montalvo-Ortiz et al., 2017). However, if such effects of HDAC inhibitors in the brain display a dose response has not been studied.

Histone modifications also play an important role in memory function during aging. Growing studies have used a wide range of HDAC inhibitors such as pan targeting HDACs or specific targeting HDAC for subclasses in aging and neurodegenerative models (Guan et al., 2009; Hahnen et al., 2008; Reolon et al., 2011). Studies have also shown that decreases or dysregulation of acetylation in the hippocampus greatly contributes to the increase of memory impairment in normal aging (Peleg et al., 2010; Castellano et al., 2012; Sen, 2015). For example, suberoylanilide hydroxamic acid (SAHA, a class 1 HDAC inhibitor) and VPA (broad acting) were able to ameliorate memory deficits, suggesting that HDAC inhibitors may have a potential to improve neuronal function and slow the progression or reverse cognitive deficits in aged patients (Reolon et al., 2011; Benito et al., 2015; Zhao et al., 2018).

Tacedinaline (CI-994), a novel selective class 1 HDAC inhibitor has been well investigated in cancer research, and recent evidence indicates that CI-994 has an impact on the central nervous system (Graff et al., 2014; Zhang et al., 2018; Fuller et al., 2019). In particular, studies have shown CI-994 could improve synaptic plasticity and memory function in mice (Graff et al., 2014; Fuller et al., 2019), however, there are no reports of whether CI-994 could reverse antipsychotic drug induced side effects in aged mice. In this study, we investigated the dose effects of CI-994 on typical antipsychotic drug HAL-induced motor and memory side effects in aged mice.

\section{EXPERIMENTAL PROCEDURES}

\section{Animals}

Young (2-3 months old, total $n=36)$ and aged (21 months old, total $n=44)$ C57BL/6 male and female mice were equally distributed in each experimental group ( $n=6-11$ for behavioral tests, $n=4-6 /$ group for biochemical analysis) from Charles River laboratories were used for this study. Animals were group housed on a 12-h light/dark cycle and given food and water ad libitum. All procedures in animals were performed according to NIH guidelines and the Current Guide for the Care and Use of Laboratory Animals (2011, eight edition) under a protocol approved by the Northwestern University Animal Care and Use Committee.

\section{Drugs}

Antipsychotic drug HAL was purchased from Sigma (St. Louis, MO, United States), and CI-994 was purchased from MedChemExpress (Monmouth Junction, NJ, United States) with inhibition of $\mathrm{IC}_{50} \mathrm{~s}$ of $0.9,0.9,1.2 \mu \mathrm{M}$ for recombinant HDAC 1,2 and 3 . HAL $(0.05 \mathrm{mg} / \mathrm{kg})$ was first dissolved in $50 \mathrm{uL}$ of glacial acetic acid and brought up to the final dose volume in $0.9 \%$ saline with $\mathrm{pH}$ adjusted with $0.1 \mathrm{M}$ $\mathrm{NaOH}$. We selected HAL at a dose of $0.05 \mathrm{mg} / \mathrm{kg}$ for our study because our previous work showed a range of 0.01$0.1 \mathrm{mg} / \mathrm{kg}$ of HAL to induce EPS-like behaviors in aged mice (Montalvo-Ortiz et al., 2017). For CI-994, 10, 20, or $30 \mathrm{mg} / \mathrm{kg}$ was dissolved in $2 \%$ DMSO and brought up the final dose volume in $0.9 \%$ saline with $\mathrm{pH}$ adjusted with $0.1 \mathrm{M} \mathrm{NaOH}$. Drugs were prepared freshly on the day of administration. All compounds and vehicles were administered intraperitoneally (i.p.) at a constant volume of $10 \mu \mathrm{L} / \mathrm{g}$ of body weight once a day for 14 consecutive days (Supplementary Figure 1). CI-994 was 
injected 30 min before HAL administration. Immediately after drug administration, we carefully monitored animal physical condition and behaviors, including: respiratory stress, locomotor function and body weight. Respiratory distress was determined by breathing patterns in mice. If fast/short, labored breathing was observed for more than $30 \mathrm{~min}$ after injections, and this symptom persisted 1 day post injections was marked as respiratory distress. General locomotor activity was monitored by observation 5, 10, and $20 \mathrm{~min}$ after first day of injections. Then we measured locomotor activity $30 \mathrm{~min}$ after the first day of injections using the open field test. Locomotor function impairments were considered if a mouse movement was greatly reduced or no movement was shown compared to control mice for more than $30 \mathrm{~min}$ after drug administration. Body weight was measured daily, and any weight loss ( $>2 \mathrm{~g}$ ) within 2-3 days was considered a significant side effect.

\section{Behavioral Tests}

Mice were acclimated to a soundproof behavioral testing room $30 \mathrm{~min}$ prior to testing, and assays were performed during the light part of the 12-h light/dark cycle. Memory and motor function tests were conducted during the second week of drug administration (Supplementary Figure 1). The purpose of our experimental design was trying to reveal the maximum drug effects in 14 days including a long-term (14 days) and short-term (30-60 min) effects of HDAC inhibitor and antipsychotic drug on memory and motor behavior. Similar experimental designs have been reported in previous studies in our group or others (Dong et al., 2005; Martin et al., 2005; Xu et al., 2010; Song et al., 2016; Montalvo-Ortiz et al., 2017). The order of the behavioral test was as follow: Novel object recognition (NOR), rotarod, and catalepsy (Supplementary Figure 1). The behavioral tests and data analysis were conducted by one investigator that was blinded to age and treatment conditions.

\section{Catalepsy}

The Step-Down assay was used for cataleptic behavior. Briefly, a plastic rod (1-cm diameter) was suspended $3.5 \mathrm{~cm}$ above a laboratory bench in a soundproof behavioral room. Thirty minutes after drug injection, the front paws of the animal were placed on the rod while the hind paws rested on the bench. The duration of a cataleptic episode was defined as the time to step off from the rod during a 300-s trial (Fink-Jensen et al., 2011; Montalvo-Ortiz et al., 2017).

\section{Motor Coordination}

The TSE Rotarod System (Bad, Homburg, Germany) was used to assess motor coordination after drug treatment. Mice were placed on an accelerating rod (4-40 rpm during the first $5 \mathrm{~min}$ ) for $10 \mathrm{~min}$, and the latency to fall from the rod was recorded. A total of 3 trials were conducted with a 10-min inter-trial interval. The average latency to fall from the rod across the 3 trials was calculated and used for comparison (Kirschbaum et al., 2009; Montalvo-Ortiz et al., 2017).

\section{Novel Object Recognition}

Recognition memory was tested in an open plexiglass box $(40 \mathrm{~cm} \times 40 \mathrm{~cm} \times 30 \mathrm{~cm})$. Two sets of objects were used, and they were consistent in height and volume, but different in shape, color and texture. Mice were individually habituated to the test arena for $10 \mathrm{~min}$ on each of the 3 days prior to data acquisition. On the first day of habituation, a open field test for mouse locomotor activity and anxiety behavior were recorded to ensure the mice had no severe impairments in locomotor function and anxiety behavior due to antipsychotic drug and CI-994 administration. The experimental session consisted of 3 phases: acquisition trial (10 $\mathrm{min}$ ), inter-trial interval (ITI; home-cage, $1 \mathrm{~h}$ ), and retention trial (10 min). During acquisition, animals were recorded while exploring the arena with two glass, cylinder-shaped identical objects that are dark gray color (height of $8 \mathrm{~cm}$ and a diameter of $4 \mathrm{~cm}$ ) placed diagonally across from each other. Following the ITI, during which one of the objects was replaced by a novel object that is plastic, prism-shaped with a yellow and blue color ( $6 \mathrm{~cm}$ length $\times 6.5 \mathrm{~cm}$ width $\times 6 \mathrm{~cm}$ height), in a counterbalanced manner, animals were placed back in the arena for the retention trial. The amount of time spent exploring each object during the acquisition and retention trial was scored by an experimenter blinded to the condition using two milliseconds stopwatches for precision. Exploration was defined as touching, leaning on the object or orienting the head towards the object and sniffing within $<1.0 \mathrm{~cm}$ for at least $20 \mathrm{~s}$ to make sure the sensorial perception was not impaired. Climbing on top of the object was not counted as exploration. Between each trial, the arena and the objects were cleaned with $70 \%$ alcohol to eliminate olfactory traces. The time spent with each object during the retention trial was used to calculate the discrimination index (DI), which represents the difference in exploration time expressed as a proportion of the total time spent exploring the two objects. To calculate DI, the total time spent exploring the novel object was subtracted by the total time spent exploring the familiar object, divided by the total time spent exploring during the retention trial. The formula used to calculate DI is as follows:

$$
=\frac{-\left(\begin{array}{c}
(\text { Total time spent exploring novel object }) \\
\text { time spent exploring familiar object })
\end{array}\right.}{\text { Total time spent exploring }}
$$

\section{Biochemical Analysis}

For biochemical assessments, only $20 \mathrm{mg} / \mathrm{kg}$ CI-994 treatment groups were measured, as this dosage combined HAL was more effective on motor and memory function in aged mice.

\section{Western Blot}

After behavioral test, we collected brain tissues through a cardiac perfusion with $0.1 \mathrm{M}$ PBS solution for $1 \mathrm{~min}$, to wash-out the blood from blood vessels in the mouse brain first. The brains were then removed and quickly dissected under ice with a dissecting scope. The striatum and prefrontal cortex were frozen at $-80^{\circ} \mathrm{C}$ until ready for processing for molecular analysis. The abundance of dopamine 2 receptor (D2R) were determined in lysates of striatum and prefrontal cortex. Protein extraction was performed by homogenizing approximately $40 \mathrm{mg}$ of tissue 
of each brain subregion in a mix of ice-cold RIPA buffer (catalog \# R0278, Sigma-Aldrich, St. Louis, MO, United States) and protease inhibitor cocktail solution (catalog \# PI78410, Fisher Scientific, Hampton, NH, United States). Tissues were processed first by using a cordless motor connected to a Teflon pestle (20 s; catalog \# 12-141-362, Fisher Scientific, Hampton, $\mathrm{NH}$, United States) followed by sonication with Branson 450 Digital Sonifier (amplitude 70\%, 2-3 s; catalog \# B450, Marshall Scientific, Hampton, NH). Samples were then centrifuged at 20,000 $\mathrm{g}$ for $10 \mathrm{~min}$ at $4^{\circ} \mathrm{C}$ and supernatants were collected for determination of total protein concentration. Protein content was measured using the Pierce ${ }^{\mathrm{TM}}$ BCA protein assay kit (catalog \# PIA53226, Fisher Scientific, Hampton, NH, United States, 2019). An equal amount of proteins $(20 \mu \mathrm{g})$ were loaded and resolved through electrophoresis in $10 \%$ Criterion $^{\mathrm{TM}}$ TGX Stain-Free ${ }^{\mathrm{TM}}$ Precast Gels at $100 \mathrm{~V}$ for $1.5 \mathrm{~h}$ (catalog \# 5671035, Biorad, Hercules, CA, United States, 2019). Proteins were transferred onto a polyvinylidene difluoride membrane by using Trans-Blot ${ }^{\circledR}$ Semi-Dry Electrophoretic Transfer Cell at $15 \mathrm{~V}$ for $1.5 \mathrm{~h}$. Blots were exposed to $5 \%$ non-fat dry milk as blocking solution for $1 \mathrm{~h}$ at room temperature and immunostained overnight at $4^{\circ} \mathrm{C}$ with primary antibodies at 1:1000 dilution against D2R (Millipore, catalog \# AB5084P, RRID\#:AB_2094980, rabbit), and $\beta$-actin (Santa Cruz, catalog \# sc-47778, mouse). The D2R antibody immunospecificity has been tested and cross-compared to other commercially available D2R primary antibodies and has been verified in brain lysates of D2R-KO mice (Stojanovic et al., 2017). The next day, membranes were incubated with 1:5000 dilution of HRP-conjugated secondary goat anti-mouse or antirabbit antibodies for $2 \mathrm{~h}$ at room temperature. Blotted proteins were detected and quantified using ChemiDoc ${ }^{\mathrm{TM}} \mathrm{MC}$ imaging system (Biorad) and Image J Software. The levels of target protein expression were normalized to $\beta$-actin (Montalvo-Ortiz et al., 2017; Rodriguez et al., 2017).

\section{Chromatin Immunoprecipitation Assay}

The commercially available Magna $\mathrm{ChIP}^{\mathrm{TM}} \mathrm{G}$ Tissue Kit (17-20000, Millipore) was used, and the published protocol was followed (Montalvo-Ortiz et al., 2014; Montalvo-Ortiz et al., 2017). Briefly, fragmented chromatin lysate was immunoprecipitated with $5 \mu \mathrm{g}$ of antibody directed against H3K27ac and H3K18ac. The DNA-histone complex was incubated with Protein G Magnetic Beads overnight at $4^{\circ} \mathrm{C}$. The DNA-histone complex was eluted from the beads and dissociated at $654^{\circ} \mathrm{C}$ for $2 \mathrm{~h}$ under high salt conditions. Proteins were digested using proteinase $\mathrm{K}$ treatment and the associated DNA was precipitated with $100 \%$ ethanol and resuspended in $50 \mu \mathrm{L}$ of PCR grade water.

\section{Quantitative Real-Time PCR}

The levels of interaction between modified histones and the Drd2 gene promoter were determined by measuring the amount of histone-associated DNA, isolated via chromatin immunoprecipitation (ChIP), using quantitative real-time PCR (qRT-PCR). The Drd2 mRNA in the striatum and prefrontal cortex was isolated and extracted (Qiagen), then reverse transcription was performed on extracted mRNA
(Quantabio) and quantitatively amplified using qRTPCR. Drd2 (forward: 5'- CTCTTTGGACTCAACAACA CAGA $-3^{\prime}$, reverse: $5^{\prime}$ - AAGGGCACGTAGAACGAGAC $-3^{\prime}$ ) (Puighermanal et al., 2020) and $\beta$-actin (forward: $5^{\prime}$ TGTTACCAACTGGGACGACA-3', reverse: $5^{\prime}$-ACCTGGG TCATCTTTTCACG-3') primers were used. For ChIP, Drd2 promoter (forward: 5' - GCCCTATGGCTTGAAGGTAA $-3^{\prime}$, reverse: $5^{\prime}-$ GACAGGCGGCGCTAGAGT $-3^{\prime}$ ) (Kurita et al., 2012) and $\beta$-actin promoter (forward: $5^{\prime}$ GAGACATTGAATGGGGCAGT-3', reverse:5'-ATGAAGAGT TTTGGCGATGG-3') were used. Input, immunoprecipitated DNA, and cDNA amplification reactions were run in triplicate in the presence of SYBR Green (Applied Biosystems) using QuantStudio 6 Flex Real Time PCR System (Applied Biosystems, Foster City, CA, United States). Ct values from each sample were obtained using the Sequence Detector 1.1 software. Ct values were normalized to endogenous gene, beta actin, to obtain a percent input. Fold differences (drug treated versus control) were then determined using the delta delta $\mathrm{C}_{t}$ method as a previous report (Livak and Schmittgen, 2001).

\section{Statistical Analysis}

All statistical analyses were conducted using the GraphPad prism software (San Diego, CA, United States). Data are expressed as mean \pm standard error of the mean (SEM). Two-way analysis of variance (ANOVA) was used to detect treatment effects followed by a multiple comparison's analysis using Tukey's post hoc method.

\section{RESULTS}

\section{Dose Dependent Response of $\mathrm{Cl}-994$ on Haloperidol Induced Motor Side Effects}

For our study, we initially used a dose range of 10, 20, and $30 \mathrm{mg} / \mathrm{kg}$ for CI-994. This dose range was selected based on previous reports that have administered CI-994 in adult mice (Graff et al., 2014; Zhang et al., 2018; Zhao et al., 2018; Fuller et al., 2019). Given HDAC inhibitors and antipsychotic drugs have their own side effects, it was critical to find the optimal dose for aged mice. We found a dose range of $10-20 \mathrm{mg} / \mathrm{kg}$ for CI-994, which showed no visible signs of physiological and neurological side effects. However, administration of $30 \mathrm{mg} / \mathrm{kg}$ with haloperidol after 3 days induced a severe side effects including respiratory stress, motor function impairment and body weight loss, especially in aged mice, therefore, we excluded this dose in our experiments.

We first tested cataleptic behavior after chronic administration of HAL, co-administration of HAL + CI-994, and CI-994 alone in young and aged mice. Two-way ANOVA revealed significant effects of age $\left(F_{1,92}=86.20, p<0.0001\right)$ and $\operatorname{drug}\left(F_{5,92}=61.82\right.$, $p<0.0001)$, and age $\times$ drug interaction $\left(F_{5,92}=56.13\right.$, $p<0.0001$ ) on cataleptic episodes (Figure 1A). Post-hoc analysis revealed aged mice administered HAL displayed severe cataleptic behavior compared to aged VEH mice $(p<0.0001)$. However, CI-994 at 10 and $20 \mathrm{mg} / \mathrm{kg}$ doses significantly decreased HAL induced cataleptic behavior (both $p<0.0001$ ), and no significant 


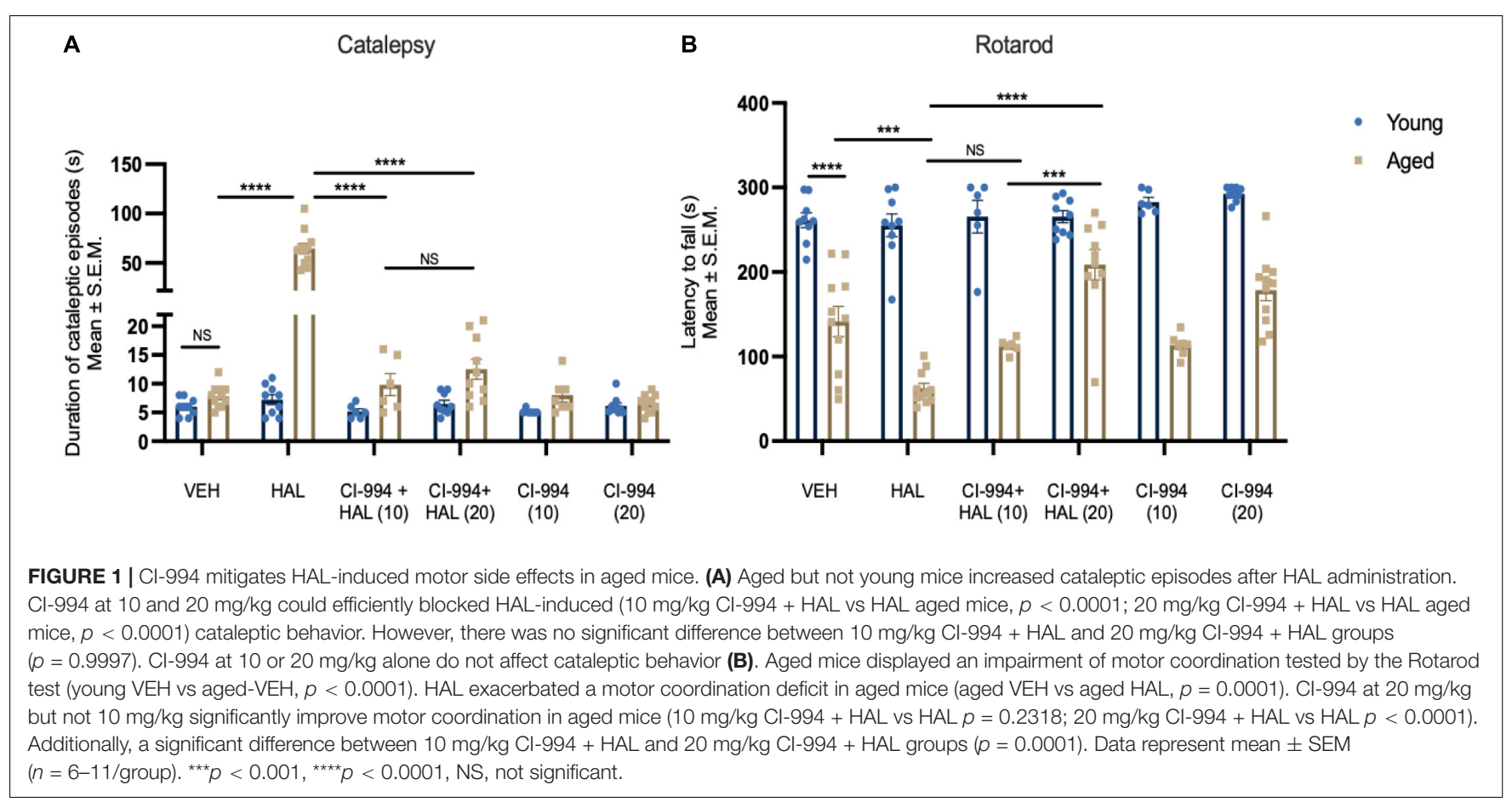

difference between 10 and $20 \mathrm{mg} / \mathrm{kg}$ groups. Also, no significant differences were found in young mice between treatment groups. These results suggest that chronic HAL administration induces severe cataleptic behavior in aged mice, and CI-994 at 10$20 \mathrm{mg} / \mathrm{kg}$ are able to mitigate this side effect.

Next, we evaluated the impact of CI-994 on HAL-induced motor coordination deficits in young and aged mice using the rotarod test. Two-way ANOVA revealed significant effects of age $\left(F_{1,92}=336.0, p<0.0001\right)$ and $\operatorname{drug}\left(F_{5,92}=8.056, p<0.0001\right)$, and an age $\mathrm{x}$ drug interaction $\left(F_{5,92}=7.537, p<0.0001\right)$ on the latency to fall from the rod (Figure 1B). Post-hoc analysis showed a significant decline of motor coordination in aged mice compared to young mice $(p<0.0001)$ and HAL accelerated a decline of motor coordination in aged mice $(p=0.0001)$. When CI-994 was administered with HAL, only $20 \mathrm{mg} / \mathrm{kg}$ showed a significant improvement in motor coordination compared HAL $(p<0.0001)$ alone. Additionally, aged mice with $20 \mathrm{mg} / \mathrm{kg}$ CI-994 + HAL showed a significant increase in the latency to fall compared to $10 \mathrm{mg} / \mathrm{kg}$ CI-994 $+\mathrm{HAL}(p=0.0048)$. No statistical differences were found in young mice between treatment groups. These results suggest that motor coordination declines in normal aging, and chronic administration of HAL exacerbates the motor coordination impairment. However, CI994 at a dosage of $20 \mathrm{mg} / \mathrm{kg}$, is sufficient to mitigate this side effect and improve motor coordination in aged mice.

\section{Dose Dependent Effects of $\mathrm{Cl}-994$ on Haloperidol Induced Memory Impairment}

In addition to motor effects, in this study, we also investigated whether HAL could induce a memory impairment in aged mice and whether HDAC inhibition could reverse such an effect.
We measured recognition memory through the novel object recognition (NOR) test. Two-way ANOVA revealed effects of age $\left(F_{1,92}=20.83, p<0.0001\right)$ and drug $\left(F_{5,92}=10.87, p<0.0001\right)$, and an age $\times$ drug interaction $\left(F_{5,92}=5.298, p=0.0003\right)$ in the recognition memory after HAL and CI-994 administration (Figure 2). Post-hoc analysis revealed no significant difference

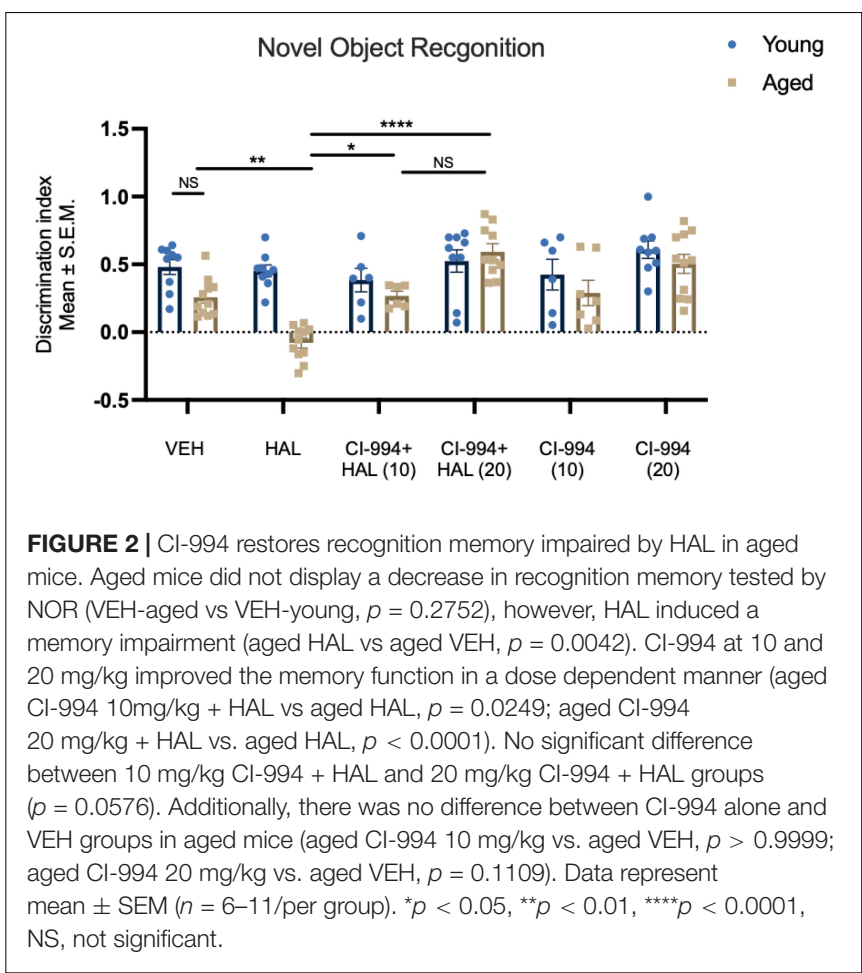


between young and aged $\mathrm{VEH}$ mice in the discrimination index (DI). However, there was a significant decrease of DI in HALtreated aged mice as compared to $\mathrm{VEH}$-treated aged control $(p=0.0042)$. Administration of CI-994 with HAL showed a significant increase of DI at a dosage of $10 \mathrm{mg} / \mathrm{kg}(p=0.0249)$ and $20 \mathrm{mg} / \mathrm{kg}(p<0.0001)$ as compared to HAL treated alone in aged mice. We found a trend of increased memory function in aged mice after $20 \mathrm{mg} / \mathrm{kg}$ CI-994 + HAL compared to $10 \mathrm{mg} / \mathrm{kg}$ CI-994 + HAL, although the statistical analysis did not reach the significant ( $p=0.0576$ ). Also, no significant differences were found in young mice between treatments groups. This data suggests that chronic administration of HAL induces recognition memory impairment and CI-994 at 10 and $20 \mathrm{mg} / \mathrm{kg}$ could restore memory function impaired by HAL in aged mice, and CI-994 + HAL at a dosage of $20 \mathrm{mg} / \mathrm{kg}$ tends to be more efficient.

\section{Effect of Cl-994 on Drd2 Gene Expression in the Prefrontal Cortex and Striatum of Aged Mice}

We determined whether CI-994 could mediate Drd2 gene expression in the prefrontal cortex and striatum, which was conducted through qRT-PCR. Two-way ANOVA revealed significant effects of age $\left(F_{1,24}=84.16, p<0.0001\right)$, drug $\left(F_{3,24}=4.822, p=0.0091\right)$, and an age $\times$ drug interaction $\left(F_{3,24}=7.427, p=0.0011\right)$ of Drd2 mRNA expression in the striatum (Figure 3A). Post hoc analysis showed a significant decrease in Drd2 mRNA expression in aged mice as compared to young mice $(p=0.0007)$ in VEH groups. However, a significant increase of Drd2 mRNA expression in the striatum of CI$994+$ HAL group as compared to the groups of VEH $(p=0.0060)$ and HAL alone $(p<0.0001)$ in aged mice. No significant differences were found in young mice between treatment groups. Additionally, Drd2 gene expression was not statistically different between young and aged mice in $\mathrm{VEH}$ groups and across treatment in the prefrontal cortex (Figure 3B).

\section{Effect of Cl-994 on D2R Protein Expression in the Prefrontal Cortex and Striatum of Aged Mice}

Our previous study indicates that D2R protein expression decreased in the striatum in aged mice and HDAC inhibitors VPA and MS-275 could modulate D2R expression (MontalvoOrtiz et al., 2017). In this study, we determined whether CI-994 also could mediate D2R expression in the prefrontal cortex and striatum. Two-way ANOVA revealed significant effects of age $\left(F_{1,33}=29.56, p<0.0001\right)$, drug $\left(F_{3,33}=5.233, p=0.00046\right)$, and an age $\times$ drug interaction $\left(F_{3,33}=3.130, p=0.0387\right)$ in $\mathrm{D} 2 \mathrm{R}$ expression in the striatum (Figures $4 \mathrm{~A}, \mathrm{~B}$ ). Post hoc analysis showed a significant decrease in $\mathrm{D} 2 \mathrm{R}$ expression in aged mice as compared to young mice $(p=0.0011)$ in $\mathrm{VEH}$ groups. Administration of CI-994 with HAL showed a significant increase of $\mathrm{D} 2 \mathrm{R}$ expression in the striatum as compared to VEH $(p=0.0102)$ and HAL alone $(p=0.0130)$ in aged mice. No significant differences were found in young mice between treatment groups. However, D2R expression was not statistically different between young and aged mice in $\mathrm{VEH}$ groups and across treatment in the prefrontal cortex (Figures 5A,B). These results indicate that chronic administration of CI-994 at dose $20 \mathrm{mg} / \mathrm{kg}$ could rescue D2R expression in the striatum, but not prefrontal cortex, suggesting the effect of CI-994 on D2R expression is regional specific.

\section{Cl-994 Impact on Histone Modifications in the Prefrontal Cortex and Striatum of Aged Mice}

In order to further confirm epigenetic alterations in aging contributed to increased side effects of antipsychotic drugs, we investigated the status of histone acetylation at typical antipsychotic drug target, Drd2 promoter, and determined if chronic administration of CI-994 can alter the levels of histone acetylation at the $\operatorname{Drd} 2$ promoter in aged mice. We selected histone 3 lysine 27 (H3K27) and 18 acetylation (H3K18) as these histone marks have been associated with transcriptional regulation (Pham et al., 2012; Chen et al., 2019). Two-way ANOVA revealed significant effects of age $\left(F_{1,24}=235.8\right.$, $p<0.0001)$ and drug $\left(F_{3,24}=19.91, p<0.0001\right)$, and an age $\mathrm{x}$ drug interaction $\left(F_{3,24}=6.034, p=0.0033\right)$ in H3K27ac levels binding at the $\operatorname{Drd} 2$ promoter in the striatum (Figure 6A). The post-hoc analysis revealed a significant decrease of $\mathrm{H} 3 \mathrm{~K} 27 \mathrm{ac}$ levels in aged mice as compared to young mice in $\mathrm{VEH}$ groups $(p<0.0001)$. CI-994 at $20 \mathrm{mg} / \mathrm{kg}$ showed a significant increase of H3K27ac levels binding to the Drd2 promoter as compared to $\operatorname{VEH}(p=0.0006)$, and HAL $(p=0.0043)$ treated alone in aged mice. No significant differences were found in young mice between treatment groups. Similarly, two-way ANOVA revealed significant effects of age $\left(F_{1,24}=11.21, p=0.0027\right)$, drug $\left(F_{3,24}=3.532, p=0.0299\right)$, and an age $\mathrm{x}$ drug interaction $\left(F_{3,24}=3.022, p=0.0493\right)$ in H3K18ac levels at the Drd2 promoter in the striatum (Figure 6B). Post-hoc analysis revealed a significant decrease of $\mathrm{H} 3 \mathrm{~K} 18 \mathrm{ac}$ binding at the Drd2 promoter in aged as compared to young mice in VEH groups $(p=0.00357)$. However, CI-994 at dose $20 \mathrm{mg} / \mathrm{kg}$ showed an increase of $\mathrm{H} 3 \mathrm{~K} 18 \mathrm{ac}$ levels binding to the Drd2 promoter of as compared to $\mathrm{VEH}$ treated group $(p=0.00137)$ in aged mice. No significant differences were found in young mice between treatment groups.

We next evaluated the epigenetic changes occurring at Drd2 promoter in the prefrontal cortex. Two-way ANOVA revealed only a significant effect of age $\left(F_{1,24}=11.72, p=0.0022\right)$ in $\mathrm{H} 3 \mathrm{~K} 27 \mathrm{ac}$ levels (Figure 6C), and effect of age $\left(F_{1,24}=87.47\right.$, $p<0.0001)$ in $\mathrm{H} 3 \mathrm{~K} 18 \mathrm{ac}$ levels binding to the Drd2 promoter (Figure 6D) in the prefrontal cortex. Post-hoc analysis revealed a significant decrease in $\mathrm{H} 3 \mathrm{~K} 18 \mathrm{ac}$ levels binding at the Drd2 promoter, but not $\mathrm{H} 3 \mathrm{~K} 27 \mathrm{ac}$ levels, in aged mice as compared to young mice in VEH groups $(p=0.0004)$. No significant differences were found in both young and aged mice between treatment groups. Our results indicate that during normal aging, there is a decrease in $\mathrm{H} 3 \mathrm{~K} 27 \mathrm{ac}$ and H3K18ac levels at the Drd2 promoter in the striatum and a decrease of H3K18ac levels at the Drd 2 promoter in prefrontal cortex. In addition, CI-994 could rescue histone acetylation in aged mice, specifically in the striatum, which may modulate the antipsychotic induced side 


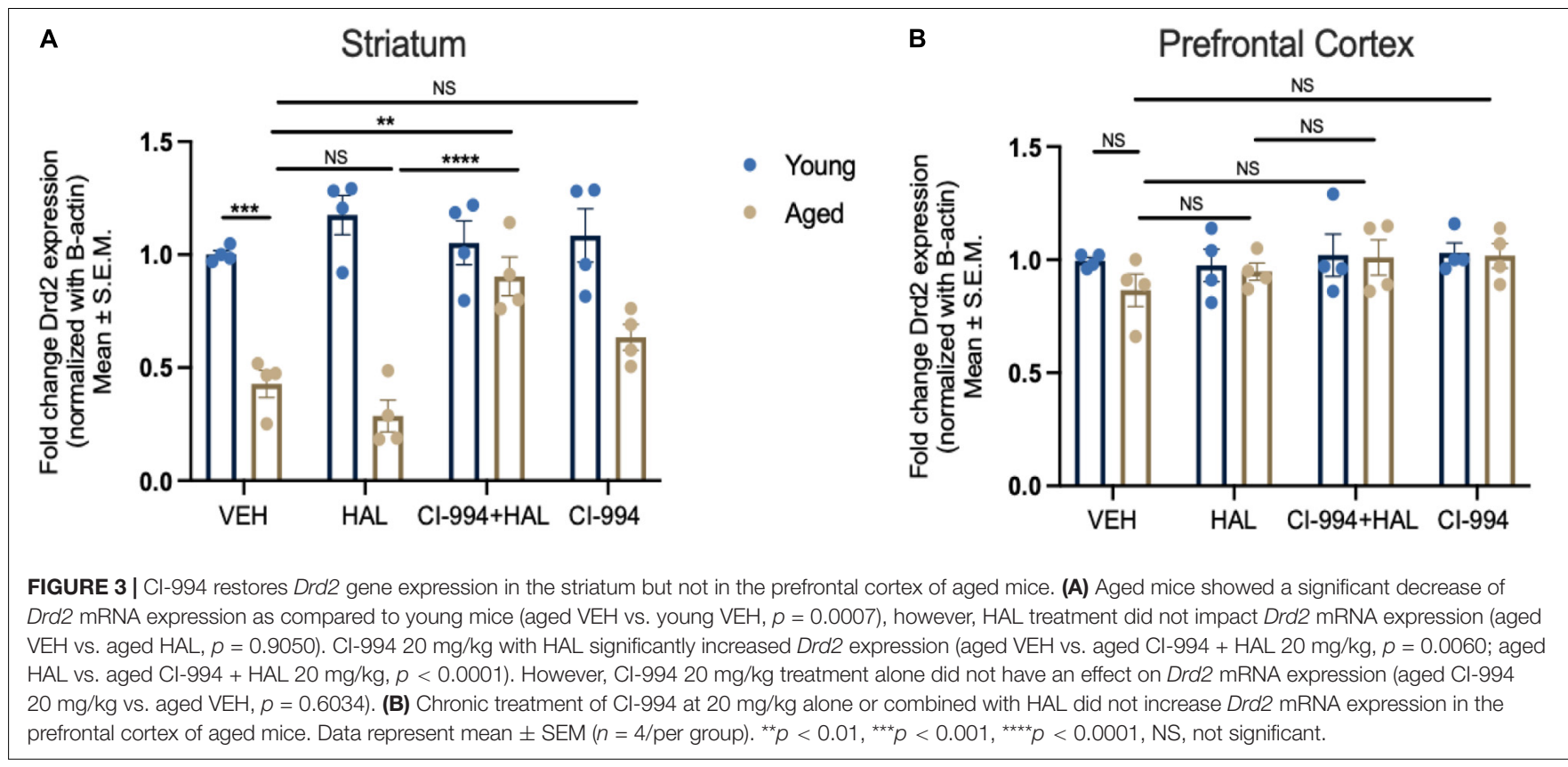

effects in aged mice through regulation of D2R expression in response to antipsychotic actions.

\section{DISCUSSION}

In this study, we demonstrated that a selective class 1 HDAC inhibitor, CI-994, can reduce the severity of motor and memory side effects in HAL treated aged mice. In particular, CI994 at doses of $10-20 \mathrm{mg} / \mathrm{kg}$ were effectively to alleviate HAL-induced cataleptic behavior, however, only CI-994 at $20 \mathrm{mg} / \mathrm{kg}$ significantly improved motor coordination in aged mice. Additionally, CI-994 at both $10-20 \mathrm{mg} / \mathrm{kg}$ mitigate HAL induced memory impairment, and it seems that CI-994 at dose of $20 \mathrm{mg} / \mathrm{kg}$ was more efficient for improving recognition memory function. The effect of CI-994 on motor function may be acting through the regulation of histone modifications at the Drd2 promoter, thus mediating $\mathrm{D} 2 \mathrm{R}$ expression in the striatum. To our knowledge, we are the first to report the benefits of CI-994 in prevention of antipsychotic drug induced motor and memory side effects in aged mice.

In this study, we not only investigated a new HDAC inhibitor, CI-994, but also tested the dose response effects of this inhibitor on antipsychotic drug induced motor and memory side effects. We selected 3 doses for CI-994, ranging from 10 to $30 \mathrm{mg} / \mathrm{kg}$, and found chronic administration of CI-994 at $30 \mathrm{mg} / \mathrm{kg}$ alone or combined with HAL induced severe side effects, including: increased respiratory distress, slower/no movement and weight loss especially in aged mice, however, mice administered CI-994 at doses of $10-20 \mathrm{mg} / \mathrm{kg}$ responded well and did not display such side effects. These results indicate that HDAC inhibitor itself could induce some side effects, or even results in toxic outcomes, which could be an impendence in preclinical research and clinical application (Subramanian et al., 2010; Gao et al., 2019;
Shah, 2019). Therefore, when testing a new compound in animal models, it is critical to carefully evaluate dose responses by measuring the physiological outcomes, in order to identify the optimal dose range. Based on our screen, we selected doses of $10-20 \mathrm{mg} / \mathrm{kg}$ to continue our experiments and conduct the behavioral and memory tests. We found that CI-994 at $10 \mathrm{mg} / \mathrm{kg}$ was only effective in decreasing cataleptic behavior, in contrast, CI-994 at $20 \mathrm{mg} / \mathrm{kg}$ was effective in decreasing cataleptic episodes and improving motor coordination (Figure 1). Although other motor assessments such as hind limb grasping and gait analysis could be applied to measure motor behavior, our results indicate both catalepsy and rotarod tests are sensitive and stable for motor function evaluation in aged mice. In fact, catalepsy has been widely used for testing extrapyramidal side effects induced by antipsychotics in preclinical studies (Bardin et al., 2006; FinkJensen et al., 2011; Nishchal et al., 2014; Luciani et al., 2020).

In our study, we also confirmed our previous reports that $\mathrm{D} 2 \mathrm{R}$ expression was decreased in the striatum of aged mice (Montalvo-Ortiz et al., 2017) and demonstrated another HDAC inhibitor CI-994 could rescue D2R expression in the aged striatum in addition to VPA and MS-275 (Montalvo-Ortiz et al., 2017). This effect was due to HDAC inhibitor mediated histone acetylation at the Drd2 gene promoter, as we found $\operatorname{Drd} 2$ mRNA expression was correlated with these changes in the striatum of aged mice. This prediction was supported by previous works, as various human and animal studies have shown significant decreases of D2R expression in the basal ganglia during aging, which has substantial impacts on target receptor binding capacities (Antonini et al., 1993; Rinne et al., 1993; Volkow et al., 1996; Tanaka et al., 2003; Hoekzema et al., 2010; Shiroma et al., 2010). Various factors such as sleep deprivation and abnormal dopaminergic neurotransmission, and posttranscriptional mechanisms could affect D2R expression during aging (Sakata et al., 1992; Meng et al., 1999; Ishibashi et al., 2009; 
A

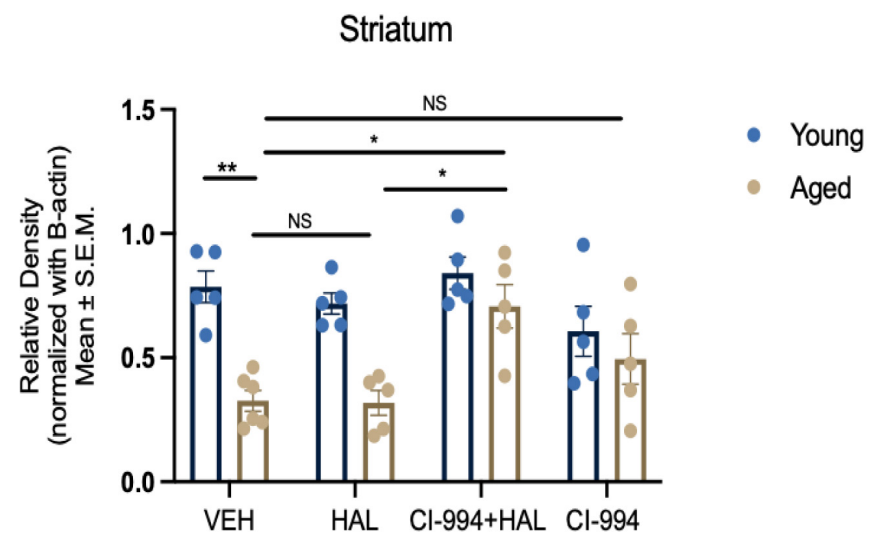

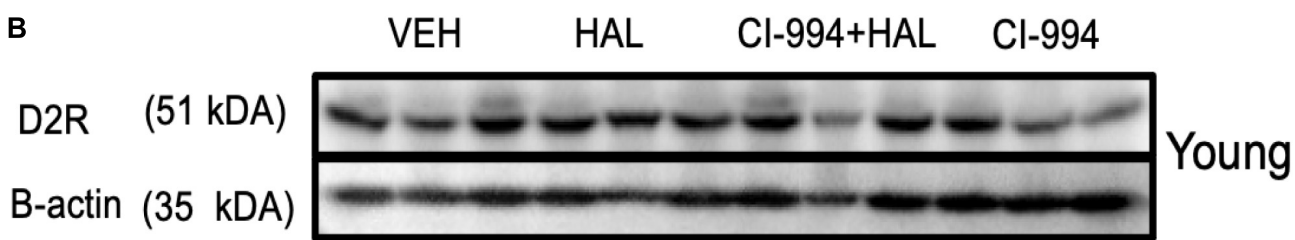

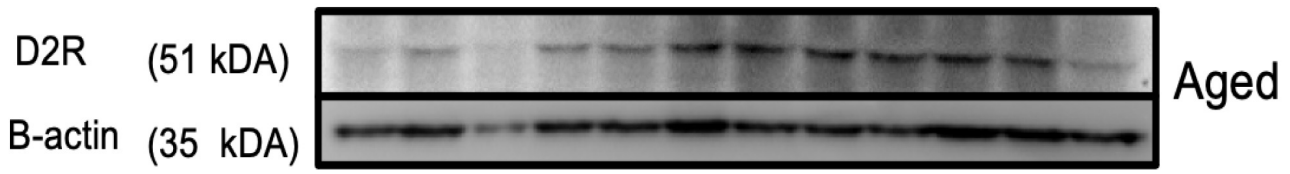

FIGURE 4 | Cl-994 restores D2R protein expression in the striatum of aged mice. (A) Quantitative analysis of D2R protein expression levels in the young and aged striatum through immunoblotting. Aged mice showed a significant decrease in D2R expression (aged VEH Vs. young VEH, $p=0.0011$ ), however, HAL treatment during aging did not impact D2R expression (aged VEH vs. aged HAL, $p>0.9999)$. Cl-994 + HAL 20 mg/kg treatment significantly increased D2R expression (aged VEH vs. aged Cl-994 + HAL 20 mg/kg, $p=0.0102$; aged HAL vs. aged Cl-994 + HAL 20 mg/kg, $p=0.0130)$. However, Cl-994 20 mg/kg treatment did not have an effect on D2R expression (aged Cl-994 $20 \mathrm{mg} / \mathrm{kg}$ vs. aged VEH, $p=0.6779$ ). (B) Western blot images from panel (A). Each band represents a different biological sample in each treatment group. Data represent mean \pm SEM $\left(n=5-6 /\right.$ per group). ${ }^{*} p<0.05,{ }^{* *} p<0.01$, NS, not significant.

Volkow et al., 2012). We proposed that histone modifications at the $\mathrm{Drd} 2$ promoter is a contributing factor for $\mathrm{D} 2 \mathrm{R}$ response to antipsychotics. Our reports demonstrated that changes of histone acetylation and methylation occurred at the Drd2 promoter region in the striatum in aged mice and HDAC inhibitors VPA and MS-275 can modify histone acetylation at Drd2 promoter by increasing acetylation (H3K27ac, H3K9ac, $\mathrm{H} 4 \mathrm{~K} 12 \mathrm{ac}$ ) levels and restore D2R expression (Montalvo-Ortiz et al., 2017). In this study, we further confirmed H3K27ac decreased with age, however, we also found another histone acetylation mark H3K18ac was decreased and CI-994 rescued acetylation of $\mathrm{H} 3 \mathrm{~K} 27 \mathrm{ac}$ and $\mathrm{H} 3 \mathrm{~K} 18 \mathrm{ac}$ at $\mathrm{Drd} 2$ promoter in the striatum of aged mice. This new information provides additional evidence that histone modifications play a critical role in drug efficacy and HDAC inhibition in conjunction with antipsychotic drug treatment, which can improve motor side effects through modulation of histone acetylation at the Drd2 promoter, subsequently modulating D2R expression and function (Montalvo-Ortiz et al., 2017). This statement is supported by our previous study, as we found the changes of downstream of D2R signaling in our previous study (MontalvoOrtiz et al., 2017) as well as our current behavioral outcomes, which reflect the function has been changed in D2Rs. Therefore, our study further supports the beneficial effects of HDAC inhibitors on antipsychotic action in aged mice.

Typical antipsychotic drugs not only increase the risk of EPS, but also increase the risk of cognitive impairment (Jeste et al., 1999; Dolder and Jeste, 2003). Many studies have reported impaired memory function after given HAL (Terry et al., 2002; Hou et al., 2006; Abdel-Salam et al., 2012; Ozdemir et al., 2012; Ning et al., 2017), and our results are consistent with these findings. The mechanisms in which HAL induces memory impairment is not clear. We found that CI-994 was able to reverse HAL induced memory impairment suggesting that histone modifications were involved. In fact, previous studies have found that CI-994 was able to improve memory function in both aging and $\mathrm{AD}$ mice through increasing histone acetylation (Graff et al., 2014; Fuller et al., 2019). The prefrontal cortex is one of various brain areas that is involved in several memory processes. However, we did not find significant changes of 
A

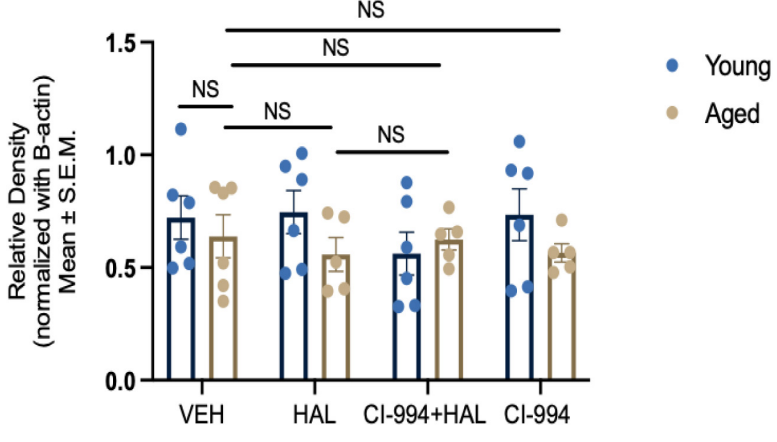

B

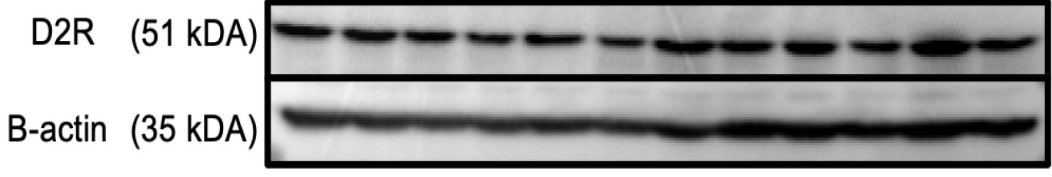

Young

Aged

FIGURE 5 | Cl-994 does not affect D2R protein expression in prefrontal cortex of aged mice (A) Quantitative analysis of D2R protein expression levels in the young and aged striatum through immunoblotting. Chronic treatment of $\mathrm{Cl}-994$ at $20 \mathrm{mg} / \mathrm{kg}$ in combination with HAL did not increase D2R protein expression in the prefrontal cortex of aged mice. (B) Western blot images from panel (A). Each band represents a different biological sample in each treatment group. Data represent mean \pm SEM ( $n=5-6 /$ per group).

D2R expression across aging and treatment in the prefrontal cortex. Additionally, CI-994 did not affect the selected histone acetylation marks at the $\operatorname{Drd} 2$ promoter in the prefrontal cortex. A possible explanation could be that D2R in the prefrontal cortex is not involved in recognition memory processes and CI-994 improving memory function in HAL treated aged mice may be through regulating histone acetylation at other genes that are associated with memory function or indirectly improved memory by decreasing drug induced side effects. Various studies have shown that histone modifications change at memory-related genes contribute to age and disease-related cognitive decline, and HDAC inhibitors can reverse such effects (Francis et al., 2009; Kilgore et al., 2010; Peleg et al., 2010; Graff et al., 2014; Yao et al., 2014; Benito et al., 2015; Cooper et al., 2020). Therefore, in future studies we plan to investigate whether HAL administration could affect the histone acetylation changes occurring at memory and synaptic plasticity-related genes in aged mice, then to determine whether HDAC inhibitors could mediate such effects. This work would help reveal the epigenetic mechanisms of how CI-994 in conjunction with HAL improve memory function through histone acetylation in memory-related transcriptional programs impacted by HAL.

We selected the striatum and the PFC to study the molecular mechanisms of antipsychotic induced severe side effects in aged mice due to their anatomical and functional relevant to neuropsychiatric disorders and are areas enriched in D2R expression. We expect that $\mathrm{D} 2 \mathrm{R}$ expression and function change during aging, which could influence antipsychotic drug actions, and these changes may be regulated by epigenetic mechanisms. However, in our study, we only found D2R expression decreased in the striatum, but not in the PFC. Additionally, CI-994 does not have an effect on D2R expression in PFC in aged mice, suggesting the striatum is more critical in response to the antipsychotic drug induced side effects in aged mice. This prediction was supported by previous works, as various human and animal studies have shown significant decreases of $\mathrm{D} 2 \mathrm{R}$ expression in the basal ganglia, but not in the cortex during aging, which has substantial impacts on target receptor binding capacities (Antonini et al., 1993; Rinne et al., 1993; Volkow et al., 1996; Tanaka et al., 2003; Hoekzema et al., 2010; Shiroma et al., 2010). Our study also indicates the epigenetic regulation in the brain are gene and regional specific. Therefore, future studies for other brain regions and different receptor genes targeted by antipsychotic drugs are needed.

Histone acetylation is one of the most common histone modifications that significantly modulates the gene transcription and functional consequences (Forsberg and Bresnick, 2001; 


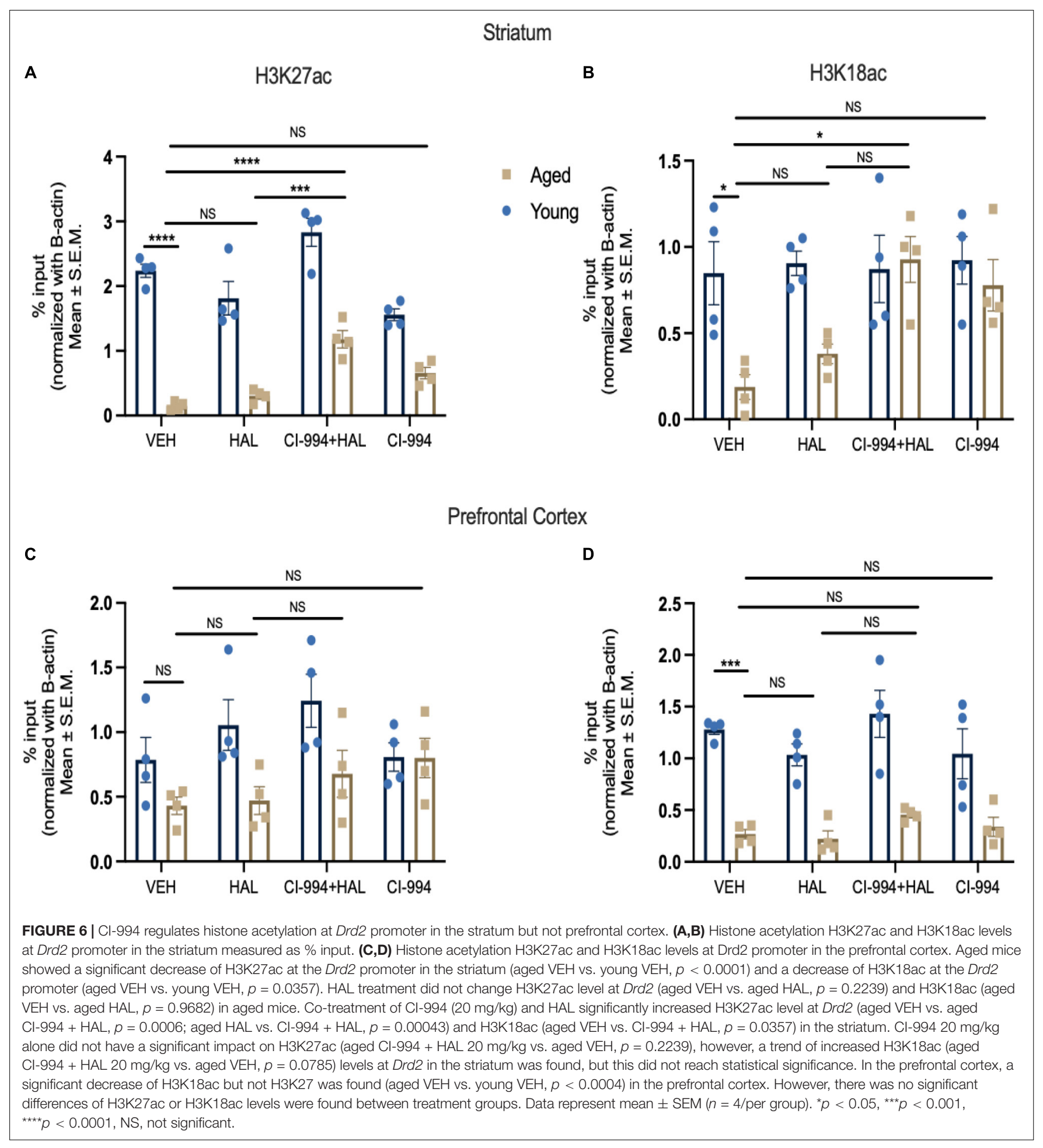

Gregory et al., 2001; Verdone et al., 2005; Verdone et al., 2006). However, other epigenetic mechanisms such as histone and DNA methylation also could affect the antipsychotic drug efficacy and memory function (Penner et al., 2011; Guidotti and Grayson, 2014; Sen, 2015; Snigdha et al., 2016; Seo et al., 2018). Additionally, besides HDACs, histone acetyltransferases
(HATs) also play an important role during the balance of the status of histone acetylation and deacetylation and play a critical role in neuronal function, which may be influencing D2R response to antipsychotic drug as well. Future studies are still necessary to investigate other epigenetic mechanisms occurring at antipsychotic drug target receptor gene promoters, to further 
prove that histone modifications play a significant role in the aging brain, which influences drug efficacy.

In summary, our results from this study demonstrate that selective class 1 HDAC inhibitor, CI-994, could reduce the age-related sensitivity to typical antipsychotic drug HALinduced motor side effects. This effect is likely that CI-994 improved the expression and functionality of D2R through modulation of histone acetylation at the $\mathrm{Drd} 2$ promoter, subsequently affecting the gene expression. CI-994 also restored memory function that was impaired due to HAL administration in aged mice. Our study suggests that CI994 may have the potential to prevent antipsychotic drug induced motor and memory side effects in the elderly. This work provides additional information to support that HDAC inhibitors could serve as a promising adjunct therapy in conjunction with typical antipsychotic drug HAL in the elderly population.

\section{DATA AVAILABILITY STATEMENT}

The raw data supporting the conclusions of this article will be made available by the authors, without undue reservation.

\section{ETHICS STATEMENT}

The animal study was reviewed and approved by Institutional Animal Care and Use Committee (IACUC) at Northwestern University.

\section{REFERENCES}

Abdel-Salam, O. M., El-Sayed El-Shamarka, M., Salem, N. A., El-Mosallamy, A. E., and Sleem, A. A. (2012). Amelioration of the haloperidol-induced memory impairment and brain oxidative stress by cinnarizine. Excli. J. 11, 517-530.

Alexopoulos, G. S., Streim, J., Carpenter, D., and Docherty, J. P. (2004). Using antipsychotic agents in older patients. J. Clin. Psychiatry 65, 5-99.

Antonini, A., Leenders, K. L., Reist, H., Thomann, R., Beer, H. F., and Locher, J. (1993). Effect of age on D2 dopamine receptors in normal human brain measured by positron emission tomography and 11C-raclopride. Arch. Neurol. 50, 474-480. doi: 10.1001/archneur.1993.00540050026010

Aupperle, P. (2006). Management of aggression, agitation, and psychosis in dementia: focus on atypical antipsychotics. Am. J. Alzheimers Dis. Other Demen. 21, 101-108. doi: 10.1177/153331750602100209

Bardin, L., Kleven, M. S., Barret-Grevoz, C., Depoortere, R., and NewmanTancredi, A. (2006). Antipsychotic-like vs cataleptogenic actions in mice of novel antipsychotics having D2 antagonist and 5-HT1A agonist properties. Neuropsychopharmacology 31, 1869-1879. doi: 10.1038/sj.npp.1300940

Benito, E., Urbanke, H., Ramachandran, B., Barth, J., Halder, R., Awasthi, A., et al. (2015). HDAC inhibitor-dependent transcriptome and memory reinstatement in cognitive decline models. J. Clin. Invest. 125, 3572-3584. doi: 10.1172/ JCI79942

Blair, D. T., and Dauner, A. (1992). Extrapyramidal symptoms are serious sideeffects of antipsychotic and other drugs. Nurse Pract. 56, 54-62.

Casey, D. E. (2004). Pathophysiology of antipsychotic drug-induced movement disorders. J. Clin. Psychiatry 65, 25-28.

Casey, D. E. (2006). Implications of the CATIE trial on treatment: extrapyramidal symptoms. CNS Spectr. 11, 25-31. doi: 10.1017/s109285290002 6651

\section{AUTHOR CONTRIBUTIONS}

BM and HD designed the experiments and supervised the project. BM was responsible for mice handling, drug preparations, i.p. injections, conducted all behavior experiments and data collection, carried out western blotting, carried out all data analysis and presentation, and wrote the manuscript. GR assisted in drug preparations. BM and GR collected mouse brain tissue, carried out chIP+qPCR. HD and GR revised the manuscript. All authors read and approved the final version of the manuscript.

\section{FUNDING}

This study was supported by NIMH grant 1R01MH109466-02 and diversity supplement MH109466s to HD.

\section{SUPPLEMENTARY MATERIAL}

The Supplementary Material for this article can be found online at: https://www.frontiersin.org/articles/10.3389/fnins. 2021.674745/full\#supplementary-material

Supplementary Figure 1 | Schematic of Experimental Procedure. Young and aged mice were treated with VEH, HAL, Cl-994 + HAL, or Cl-994 alone for 14 days. Behavioral tests were completed during days 8-13 with order: Novel object recognition (NOR, day 9-11), rotarod (day 12), and catalepsy (day 13). On day 14 , the striatum and prefrontal cortex were dissected and collected for further biochemical assessments.

Castellano, J. F., Fletcher, B. R., Kelley-Bell, B., Kim, D. H., Gallagher, M., and Rapp, P. R. (2012). Age-related memory impairment is associated with disrupted multivariate epigenetic coordination in the hippocampus. PLoS One 7:e33249. doi: 10.1371/journal.pone.0033249

Chen, L. F., Lin, Y. T., Gallegos, D. A., Hazlett, M. F., Gomez-Schiavon, M., Yang, M. G., et al. (2019). Enhancer histone acetylation modulates transcriptional bursting dynamics of neuronal activity-inducible genes. Cell Rep. 26, 11741188. doi: 10.1016/j.celrep.2019.01.032

Cohen-Mansfield, J. (2001). Nonpharmacologic interventions for inappropriate behaviors in dementia: a review, summary, and critique. Am. J. Geriatr. Psychiatry 9, 361-381.

Cooper, A., Butto, T., Hammer, N., Jagannath, S., Fend-Guella, D. L., Akhtar, J., et al. (2020). Inhibition of histone deacetylation rescues phenotype in a mouse model of Birk-Barel intellectual disability syndrome. Nat. Commun. 11:480. doi: 10.1038/s41467-019-13918-4

Cummings, J. L., Mega, M., Gray, K., Rosenberg-Thompson, S., Carusi, D. A., and Gornbein, J. (1994). The neuropsychiatric inventory: comprehensive assessment of psychopathology in dementia. Neurology 44, 2308-2314. doi: 10.1212/wnl.44.12.2308

De Deyn, P. P., Drenth, A. F., Kremer, B. P., Oude Voshaar, R. C., and Van Dam, D. (2013). Aripiprazole in the treatment of Alzheimer's disease. Expert Opin. Pharmacother. 14, 459-474. doi: 10.1517/14656566.2013.764989

Dolder, C. R., and Jeste, D. V. (2003). Incidence of tardive dyskinesia with typical versus atypical antipsychotics in very high risk patients. Biol. Psychiatry 53, 1142-1145. doi: 10.1016/s0006-3223(03)00170-7

Dong, H., Csernansky, C. A., Martin, M. V., Bertchume, A., Vallera, D., and Csernansky, J. G. (2005). Acetylcholinesterase inhibitors ameliorate behavioral deficits in the Tg2576 mouse model of Alzheimer's disease. Psychopharmacology 181, 145-152. doi: 10.1007/s00213-005-2230-6 
Fink-Jensen, A., Schmidt, L. S., Dencker, D., Schulein, C., Wess, J., Wortwein, G., et al. (2011). Antipsychotic-induced catalepsy is attenuated in mice lacking the M4 muscarinic acetylcholine receptor. Eur. J. Pharmacol. 656, 39-44. doi: 10.1016/j.ejphar.2011.01.018

Forsberg, E. C., and Bresnick, E. H. (2001). Histone acetylation beyond promoters: long-range acetylation patterns in the chromatin world. Bioessays 23, 820-830. doi: 10.1002/bies.1117

Francis, Y. I., Fa, M., Ashraf, H., Zhang, H., Staniszewski, A., Latchman, D. S., et al. (2009). Dysregulation of histone acetylation in the APP/PS1 mouse model of Alzheimer's disease. J. Alzheimers Dis. 18, 131-139. doi: 10.3233/JAD-20091134

Fuller, N. O., Pirone, A., Lynch, B. A., Hewitt, M. C., Quinton, M. S., McKee, T. D., et al. (2019). CoREST complex-selective histone deacetylase inhibitors show prosynaptic effects and an improved safety profile to enable treatment of synaptopathies. ACS Chem. Neurosci. 10, 1729-1743. doi: 10.1021/ acschemneuro.8b00620

Gao, X., Shen, L., Li, X., and Liu, J. (2019). Efficacy and toxicity of histone deacetylase inhibitors in relapsed/refractory multiple myeloma: systematic review and meta-analysis of clinical trials. Exp. Ther. Med. 18, 1057-1068. doi: $10.3892 /$ etm.2019.7704

Gareri, P., Segura-Garcia, C., Manfredi, V. G., Bruni, A., Ciambrone, P., Cerminara, G., et al. (2014). Use of atypical antipsychotics in the elderly: a clinical review. Clin. Interv. Aging 9, 1363-1373. doi: 10.2147/CIA.S63942

Graff, J., Joseph, N. F., Horn, M. E., Samiei, A., Meng, J., Seo, J., et al. (2014). Epigenetic priming of memory updating during reconsolidation to attenuate remote fear memories. Cell 156, 261-276. doi: 10.1016/j.cell.2013.12.020

Gregory, P. D., Wagner, K., and Horz, W. (2001). Histone acetylation and chromatin remodeling. Exp. Cell Res. 265, 195-202. doi: 10.1006/excr.2001. 5187

Guan, J. S., Haggarty, S. J., Giacometti, E., Dannenberg, J. H., Joseph, N., Gao, J., et al. (2009). HDAC2 negatively regulates memory formation and synaptic plasticity. Nature 459, 55-60. doi: 10.1038/nature07925

Guidotti, A., and Grayson, D. R. (2014). DNA methylation and demethylation as targets for antipsychotic therapy. Dialogues Clin. Neurosci. 16, 419-429.

Hahnen, E., Hauke, J., Trankle, C., Eyupoglu, I. Y., Wirth, B., and Blumcke, I. (2008). Histone deacetylase inhibitors: possible implications for neurodegenerative disorders. Expert Opin. Investig. Drugs 17, 169-184. doi: 10.1517/13543784.17.2.169

Hoekzema, E., Herance, R., Rojas, S., Pareto, D., Abad, S., Jimenez, X., et al. (2010). The effects of aging on dopaminergic neurotransmission: a microPET study of [11C]-raclopride binding in the aged rodent brain. Neuroscience 171, 1283-1286. doi: 10.1016/j.neuroscience.2010.10.012

Hou, Y., Wu, C. F., Yang, J. Y., and Guo, T. (2006). Differential effects of haloperidol, clozapine and olanzapine on learning and memory functions in mice. Prog. Neuropsychopharmacol. Biol. Psychiatry 30, 1486-1495. doi: 10. 1016/j.pnpbp.2006.06.001

Ishibashi, K., Ishii, K., Oda, K., Kawasaki, K., Mizusawa, H., and Ishiwata, K. (2009). Regional analysis of age-related decline in dopamine transporters and dopamine D2-like receptors in human striatum. Synapse 63, 282-290. doi: 10.1002/syn.20603

Jeste, D. V., Lacro, J. P., Bailey, A., Rockwell, E., Harris, M. J., and Caligiuri, M. P. (1999). Lower incidence of tardive dyskinesia with risperidone compared with haloperidol in older patients. J. Am. Geriatr. Soc. 47, 716-719. doi: 10.1111/j. 1532-5415.1999.tb01595.x

Kamble, P., Chen, H., Sherer, J., and Aparasu, R. R. (2008). Antipsychotic drug use among elderly nursing home residents in the United States. Am. J. Geriatr. Pharmacother. 6, 187-197. doi: 10.1016/j.amjopharm.2008.10.002

Kilgore, M., Miller, C. A., Fass, D. M., Hennig, K. M., Haggarty, S. J., Sweatt, J. D., et al. (2010). Inhibitors of class 1 histone deacetylases reverse contextual memory deficits in a mouse model of Alzheimer's disease. Neuropsychopharmacology 35, 870-880. doi: 10.1038/npp.2009.197

Kirschbaum, K. M., Hiemke, C., and Schmitt, U. (2009). Rotarod impairment: catalepsy-like screening test for antipsychotic side effects. Int. J. Neurosci. 119, 1509-1522.

Kurita, M., Holloway, T., Garcia-Bea, A., Kozlenkov, A., Friedman, A. K., Moreno, J. L., et al. (2012). HDAC2 regulates atypical antipsychotic responses through the modulation of mGlu2 promoter activity. Nat. Neurosci. 15, 1245-1254. doi: $10.1038 / \mathrm{nn} .3181$
Livak, K. J., and Schmittgen, T. D. (2001). Analysis of relative gene expression data using real-time quantitative PCR and the 2(-Delta Delta C(T)) Method. Methods 25, 402-408. doi: 10.1006/meth.2001.1262

Luciani, K. R., Frie, J. A., and Khokhar, J. Y. (2020). An Open Source Automated Bar Test for Measuring Catalepsy in Rats. eNeuro 7:20. doi: 10.1523/ENEURO. 0488-19.2020

Martin, M. V., Dong, H., Bertchume, A., and Csernansky, J. G. (2005). Low dose quetiapine reverses deficits in contextual and cued fear conditioning in rats with excitotoxin-induced hippocampal neuropathy. Pharmacol. Biochem. Behav. 82, 263-269. doi: 10.1016/j.pbb.2005.08.010

McClarty, B. M., Fisher, D. W., and Dong, H. (2018). Epigenetic alterations impact on antipsychotic treatment in elderly patients. Curr. Treat. Options Psychiatry $5,17-29$.

Meltzer, H. Y. (2013). Update on typical and atypical antipsychotic drugs. Annu. Rev. Med. 64, 393-406. doi: 10.1146/annurev-med-050911-161504

Meng, S. Z., Ozawa, Y., Itoh, M., and Takashima, S. (1999). Developmental and agerelated changes of dopamine transporter, and dopamine D1 and D2 receptors in human basal ganglia. Brain Res. 843, 136-144. doi: 10.1016/s0006-8993(99) 01933-2

Montalvo-Ortiz, J. L., Fisher, D. W., Rodriguez, G., Fang, D., Csernansky, J. G., and Dong, H. (2017). Histone deacetylase inhibitors reverse age-related increases in side effects of haloperidol in mice. Psychopharmacology 234, 2385-2398. doi: 10.1007/s00213-017-4629-2

Montalvo-Ortiz, J. L., Keegan, J., Gallardo, C., Gerst, N., Tetsuka, K., Tucker, C., et al. (2014). HDAC inhibitors restore the capacity of aged mice to respond to haloperidol through modulation of histone acetylation. Neuropsychopharmacology 39, 1469-1478. doi: 10.1038/npp.2013.346

Ning, H., Cao, D., Wang, H., Kang, B., Xie, S., and Meng, Y. (2017). Effects of haloperidol, olanzapine, ziprasidone, and PHA-543613 on spatial learning and memory in the Morris water maze test in naive and MK-801-treated mice. Brain Behav. 7:e00764. doi: 10.1002/brb3.764

Nishchal, B. S., Rai, S., Prabhu, M. N., Ullal, S. D., Rajeswari, S., and Gopalakrishna, H. N. (2014). Effect of Tribulus terrestris on haloperidol-induced catalepsy in mice. Indian J. Pharm. Sci. 76, 564-567.

Ozdemir, H., Ertugrul, A., Basar, K., and Saka, E. (2012). Differential effects of antipsychotics on hippocampal presynaptic protein expressions and recognition memory in a schizophrenia model in mice. Prog. Neuropsychopharmacol. Biol. Psychiatry 39, 62-68. doi: 10.1016/j.pnpbp. 2012.05.009

Peleg, S., Sananbenesi, F., Zovoilis, A., Burkhardt, S., Bahari-Javan, S., Agis-Balboa, R. C., et al. (2010). Altered histone acetylation is associated with age-dependent memory impairment in mice. Science 328, 753-756. doi: 10.1126/science. 1186088

Peluso, M. J., Lewis, S. W., Barnes, T. R., and Jones, P. B. (2012). Extrapyramidal motor side-effects of first- and second-generation antipsychotic drugs. Br. J. Psychiatry 200, 387-392. doi: 10.1192/bjp.bp.111.101485

Penner, M. R., Roth, T. L., Chawla, M. K., Hoang, L. T., Roth, E. D., Lubin, F. D., et al. (2011). Age-related changes in Arc transcription and DNA methylation within the hippocampus. Neurobiol. Aging 32, 2198-2210. doi: 10.1016/j. neurobiolaging.2010.01.009

Pham, T. H., Benner, C., Lichtinger, M., Schwarzfischer, L., Hu, Y., Andreesen, R., et al. (2012). Dynamic epigenetic enhancer signatures reveal key transcription factors associated with monocytic differentiation states. Blood 119, e161-e171. doi: 10.1182/blood-2012-01-402453

Puighermanal, E., Castell, L., Esteve-Codina, A., Melser, S., Kaganovsky, K., Zussy, C., et al. (2020). Functional and molecular heterogeneity of D2R neurons along dorsal ventral axis in the striatum. Nat. Commun. 11:1957. doi: 10.1038/s41467020-15716-9

Reolon, G. K., Maurmann, N., Werenicz, A., Garcia, V. A., Schroder, N., Wood, M. A., et al. (2011). Posttraining systemic administration of the histone deacetylase inhibitor sodium butyrate ameliorates aging-related memory decline in rats. Behav. Brain Res. 221, 329-332. doi: 10.1016/j.bbr.2011.03.033

Rinne, J. O., Hietala, J., Ruotsalainen, U., Sako, E., Laihinen, A., Nagren, K., et al. (1993). Decrease in human striatal dopamine D2 receptor density with age: a PET study with [11C]raclopride. J. Cereb. Blood Flow Metab. 13, 310-314. doi: 10.1038/jcbfm.1993.39

Rodriguez, G., Neugebauer, N. M., Yao, K. L., Meltzer, H. Y., Csernansky, J. G., and Dong, H. (2017). Delta9-tetrahydrocannabinol (Delta9-THC) administration 
after neonatal exposure to phencyclidine potentiates schizophrenia-related behavioral phenotypes in mice. Pharmacol. Biochem. Behav. 159, 6-11. doi: 10.1016/j.pbb.2017.06.010

Sakata, M., Farooqui, S. M., and Prasad, C. (1992). Post-transcriptional regulation of loss of rat striatal D2 dopamine receptor during aging. Brain Res. 575, 309-314. doi: 10.1016/0006-8993(92)90095-q

Schneider, L. S., Pollock, V. E., and Lyness, S. A. (1990). A metaanalysis of controlled trials of neuroleptic treatment in dementia. J. Am. Geriatr. Soc. 38, 553-563. doi: 10.1111/j.1532-5415.1990.tb02407.x

Sen, N. (2015). Epigenetic regulation of memory by acetylation and methylation of chromatin: implications in neurological disorders, aging, and addiction. Neuromolecular. Med. 17, 97-110. doi: 10.1007/s12017-0148306-x

Seo, M. K., Kim, Y. H., McIntyre, R. S., Mansur, R. B., Lee, Y., Carmona, N. E., et al. (2018). Effects of antipsychotic drugs on the epigenetic modification of brain-derived neurotrophic factor gene expression in the hippocampi of chronic restraint stress rats. Neural. Plast. 2018:2682037. doi: 10.1155/2018/268 2037

Shah, R. R. (2019). Safety and Tolerability of Histone Deacetylase (HDAC) Inhibitors in Oncology. Drug Saf. 42, 235-245. doi: 10.1007/s40264-018-0 773-9

Shiroma, P. R., Geda, Y. E., and Mrazek, D. A. (2010). Pharmacogenomic implications of variants of monoaminergic-related genes in geriatric psychiatry. Pharmacogenomics 11, 1305-1330. doi: 10.2217/pgs. 10.118

Snigdha, S., Prieto, G. A., Petrosyan, A., Loertscher, B. M., Dieskau, A. P., Overman, L. E., et al. (2016). H3K9me3 inhibition improves memory, promotes spine formation, and increases BDNF levels in the aged hippocampus. J. Neurosci. 36, 3611-3622. doi: 10.1523/JNEUROSCI.2693-15.2016

Song, J. C., Seo, M. K., Park, S. W., Lee, J. G., and Kim, Y. H. (2016). Differential effects of olanzapine and haloperidol on MK-801-induced memory impairment in mice. Clin. Psychopharmacol. Neurosci. 14, 279-285. doi: 10.9758/cpn.2016. 14.3.279

Stojanovic, T., Orlova, M., Sialana, F. J., Hoger, H., Stuchlik, S., Milenkovic, I., et al. (2017). Validation of dopamine receptor DRD1 and DRD2 antibodies using receptor deficient mice. Amino. Acids 49, 1101-1109.

Subramanian, S., Bates, S. E., Wright, J. J., Espinoza-Delgado, I., and Piekarz, R. L. (2010). Clinical Toxicities of Histone Deacetylase Inhibitors. Pharmaceuticals 3, 2751-2767. doi: 10.3390/ph3092751

Tampi, R. R., Tampi, D. J., Balachandran, S., and Srinivasan, S. (2016). Antipsychotic use in dementia: a systematic review of benefits and risks from meta-analyses. Ther. Adv. Chronic. Dis. 7, 229-245. doi: 10.1177/ 2040622316658463

Tanaka, Y., Meguro, K., Yamaguchi, S., Ishii, H., Watanuki, S., Funaki, Y., et al. (2003). Decreased striatal D2 receptor density associated with severe behavioral abnormality in Alzheimer's disease. Ann. Nucl. Med. 17, 567-573.

Terry, A. V. Jr., Hill, W. D., Parikh, V., Evans, D. R., Waller, J. L., and Mahadik, S. P. (2002). Differential effects of chronic haloperidol and olanzapine exposure on brain cholinergic markers and spatial learning in rats. Psychopharmacology 164, 360-368. doi: 10.1007/s00213-002-1230-z
Verdone, L., Agricola, E., Caserta, M., and Di Mauro, E. (2006). Histone acetylation in gene regulation. Brief Funct. Genomic Proteomic 5, 209-221. doi: 10.1093/ bfgp/ell028

Verdone, L., Caserta, M., and Di Mauro, E. (2005). Role of histone acetylation in the control of gene expression. Biochem. Cell Biol. 83, 344-353. doi: 10.1139/ o05-041

Volkow, N. D., Tomasi, D., Wang, G. J., Telang, F., Fowler, J. S., Logan, J., et al. (2012). Evidence that sleep deprivation downregulates dopamine D2R in ventral striatum in the human brain. J. Neurosci. 32, 6711-6717. doi: 10.1523/ JNEUROSCI.0045-12.2012

Volkow, N. D., Wang, G. J., Fowler, J. S., Logan, J., Hitzemann, R., Ding, Y. S., et al. (1996). Decreases in dopamine receptors but not in dopamine transporters in alcoholics. Alcohol Clin. Exp. Res. 20, 1594-1598. doi: 10.1111/j.1530-0277. 1996.tb05936.x

Xu, H., Yang, H. J., McConomy, B., Browning, R., and Li, X. M. (2010). Behavioral and neurobiological changes in $\mathrm{C} 57 \mathrm{BL} / 6$ mouse exposed to cuprizone: effects of antipsychotics. Front. Behav. Neurosci. 4:8. doi: 10.3389/fnbeh.2010. 00008

Yao, Z. G., Liang, L., Liu, Y., Zhang, L., Zhu, H., Huang, L., et al. (2014). Valproate improves memory deficits in an Alzheimer's disease mouse model: investigation of possible mechanisms of action. Cell Mol. Neurobiol. 34, 805-812. doi: 10. 1007/s10571-013-0012-y

Zaudig, M. (2000). A risk-benefit assessment of risperidone for the treatment of behavioural and psychological symptoms in dementia. Drug Saf. 23, 183-195. doi: 10.2165/00002018-200023030-00002

Zhang, S., Fujita, Y., Matsuzaki, R., and Yamashita, T. (2018). Class I histone deacetylase (HDAC) inhibitor CI-994 promotes functional recovery following spinal cord injury. Cell Death Dis. 9:460. doi: 10.1038/s41419-0180543-8

Zhao, W. N., Ghosh, B., Tyler, M., Lalonde, J., Joseph, N. F., Kosaric, N., et al. (2018). Class I histone deacetylase inhibition by tianeptinaline modulates neuroplasticity and enhances memory. ACS Chem. Neurosci. 9, 2262-2273. doi: 10.1021/acschemneuro.8b00116

Conflict of Interest: The authors declare that the research was conducted in the absence of any commercial or financial relationships that could be construed as a potential conflict of interest.

Publisher's Note: All claims expressed in this article are solely those of the authors and do not necessarily represent those of their affiliated organizations, or those of the publisher, the editors and the reviewers. Any product that may be evaluated in this article, or claim that may be made by its manufacturer, is not guaranteed or endorsed by the publisher.

Copyright (C) 2021 McClarty, Rodriguez and Dong. This is an open-access article distributed under the terms of the Creative Commons Attribution License (CC BY). The use, distribution or reproduction in other forums is permitted, provided the original author(s) and the copyright owner(s) are credited and that the original publication in this journal is cited, in accordance with accepted academic practice. No use, distribution or reproduction is permitted which does not comply with these terms. 